\title{
The role of orexins/hypocretins in alcohol use and abuse: an appetitive-reward relationship
}

\author{
Andrezza K. Kim ${ }^{1,2+}$, Robyn M. Brown ${ }^{1,3+}$ and Andrew J. Lawrence ${ }^{1,3 *}$ \\ ${ }^{1}$ Addiction Neuroscience Laboratory, Behavioural Neuroscience Division, Florey Neuroscience Institutes, University of Melbourne, Parkville, VIC, Australia \\ 2 Departamento de Psicobiologia, Escola Paulista de Medicina, Universidade Federal de São Paulo, São Paulo, Brazil \\ ${ }^{3}$ Centre for Neuroscience, University of Melbourne, Parkville, VIC, Australia
}

Edited by:

Benjamin Boutrel, Lausanne

University Hospital, Switzerland

Reviewed by:

Christopher V. Dayas, University of

Newcastle, Australia

Sarah Leibowitz, The Rockefeller

University, USA

*Correspondence:

Andrew J. Lawrence, Addiction

Neuroscience Laboratory,

Behavioural Neuroscience Division,

Florey Neuroscience Institutes,

University of Melbourne, Parkville,

VIC 3010, Australia.

e-mail:andrew.lawrence@

florey.edu.au

${ }^{t}$ These authors equally contributed

to this work.
Orexins (hypocretins) are neuropeptides synthesized in neurons located in the lateral $(\mathrm{LH})$, perifornical, and dorsomedial $(\mathrm{DMH})$ hypothalamus. These neurons innervate many regions in the brain and modulate multiple other neurotransmitter systems. As a result of these extensive projections and interactions orexins are involved in numerous functions, such as feeding behavior, neuroendocrine regulation, the sleep-wake cycle, and reward-seeking. This review will summarize the literature to date which has evaluated a role of orexins in the behavioral effects of alcohol, with a focus on understanding the importance of this peptide and its potential as a clinical therapeutic target for alcohol use disorders.

Keywords: orexin, hypocretin, alcohol, relapse, reward-seeking behavior, drug-seeking, ethanol

\section{OVERVIEW}

Orexins (orexin-A, a 33-amino acid peptide, and orexin-B, a 28 -amino acid peptide), or hypocretins (hypocretin-1 and hypocretin-2) are neuropeptides derived from same precursor: pre-proorexin or pre-prohypocretin (De Lecea et al., 1998; Sakurai et al., 1998) and they are the main endogenous ligands of the orexin/hypocretin system. The name orexin was given to the peptide because it means appetitive in Greek (Sakurai et al., 1998) and hypocretin is intended to indicate a hypothalamic member of incretin family (De Lecea et al., 1998). In this review we use the term orexin to describe this system and its components.

To date, two receptors have been identified for the orexin peptides: the OX-1 receptor (OX1R), which has higher affinity orexin-A; and the OX-2 receptor (OX2R), which has equal affinity for both orexin-A and -B (Sakurai et al., 1998). The orexin receptors are members of the family of seven-transmembrane G protein-coupled cell surface receptors (Sakurai et al., 1998). OX1R reportedly couples exclusively with Gq-protein whereas OX2R has been shown to couple with Gq- and Gi/o-proteins (Zhu et al., 2003).

A number of antagonists of OX1R and OX2R have been developed by different pharmaceutical companies, initially with the goal of investigating sleep disorders. In this section we describe some examples of these compounds, our list is not intended to be exhaustive, since drug development is a dynamic and changing process. GlaxoSmithKline (GSK) developed the OX1R antagonist SB 334867, which has a $\sim 50$ fold higher affinity for OX1R than OX2R (Rodgers et al., 2001; Smart et al., 2001). The same company also developed SB
408124, SB 410220, and SB 674042 which possess varying selectivity for human OX1R over OX2R (Langmead et al., 2004; Dugovic et al., 2009). GSK has also developed a dual OX1R/OX2R antagonist, SB 649868 which is currently in phase II clinical trials for sleep disorders (Scammell and Winrow, 2011). Almorexant is another dual OX1R/OX2R antagonist, developed by Actelion (Brisbare-Roch et al., 2007; Boss et al., 2009; Malherbe et al., 2009b). Merck, in turn, has developed three dual antagonists: DORA-1, DORA-5, and [(7R)-4(5-Chloro-1,3-benzoxazol-2-yl)-7-methyl-1,4-diazepan-1-yl][5methyl-2-(2H-1,2,3-triazol-2-yl)phenyl]methanone (MK-4305) (Bergman et al., 2008; Cox et al., 2009; Whitman et al., 2009; Winrow et al., 2010). Finally, Johnson \& Johnson have developed a selective OX2R antagonist, JNJ 10397049, as has Hoffmann-La Roche with $N$-ethyl-2-[(6-methoxy-pyridin-3-yl)-(toluene-2sulphonyl)-amino]- $N$-pyridin-3-ylmethyl-acetamide (EMPA) (McAtee et al., 2004; Malherbe et al., 2009a).

Orexin-containing neurons are found in dorsomedial (DMH), lateral (LH) and perifornical hypothalamic areas (PFA) (Peyron et al., 1998). These neurons send their projections widely to multiple brain regions in the cortex, hypothalamus, brainstem, and spinal cord (Broberger et al., 1998; Elias et al., 1998; Peyron et al., 1998; Date et al., 1999; Nambu et al., 1999; Van Den Pol, 1999). Orexins can modulate noradrenergic (Hagan et al., 1999; Horvath et al., 1999; Bourgin et al., 2000), serotonergic (Brown et al., 2001, 2002), cholinergic (Burlet et al., 2002), and dopaminergic systems (Korotkova et al., 2003), as well as the hypothalamic-pituitaryadrenal axis (Jaszberenyi et al., 2000; Kuru et al., 2000). In accordance with an extensive projection network of orexin neurons and 
their established role in modulating several major neurotransmitter systems, orexins are involved in numerous physiological functions: blood pressure regulation, thermoregulation, feeding behavior, neuroendocrine regulation, the sleep-wake cycle and, more recently, drug-seeking behavior (Allen and Cechetto, 1992; Stanley et al., 1996; De Lecea et al., 1998; Peyron et al., 1998; Sakurai et al., 1998; Harris et al., 2005; Lawrence et al., 2006; Aston-Jones et al., 2009).

\section{ADDICTION}

Drug addiction (including alcohol dependence) is a chronic, relapsing disorder which consists of a compulsive pattern of drug-seeking and drug-taking behavior that takes place at the expense of other activities. Many people experiment with potentially addictive drugs and a minority become addicted; hence drug use alone does not inevitably lead to drug addiction. A key question in addiction research, therefore, is how do susceptible individuals make the transition from casual to compulsive drug use? Cellular and molecular effects of repeated drug use appear to produce long-term alterations in neural functions and ultimately remodel neuronal circuits. These changes may potentially explain how the risk of relapse from a drug-free state can persist for years, and also how drug-related cues are able to control behavior. In order to elucidate the mechanism by which the transition from drug use to addiction occurs, research is directed toward identifying and characterizing brain systems that mediate the rewarding effects of addictive drugs and if/how these brain systems are changed by drug use.

Harmful alcohol consumption is responsible for 2.5 million deaths annually, causing illness and injury to many more. According to the World Health Organization (WHO) 55\% of the adult population has consumed an alcoholic beverage at least one time in their life. In 2005, worldwide alcohol consumption was equal to 6.13 litres of pure alcohol consumed per person aged 15 years or older (WHO, 2011). Unlike drugs such as cocaine, alcohol has many pharmacological targets, acting on various signaling pathways, ion channels, and neurotransmitter systems. Examples of molecular targets include $\gamma$-aminobutyric acid (GABA), glycine (Mihic, 1999), glutamate (Lovinger et al., 1989), serotonin (Lovinger, 1999), and acetylcholine (Narahashi et al., 1999) signaling.

Despite their varying pharmacological profiles and properties, most drugs of abuse share the common feature of acutely enhancing neurotransmission in the mesocorticolimbic system. This interaction can be direct, as in the case of psychostimulants, or indirect, as in the case of opioids, but all ultimately result in increased levels of extracellular dopamine in the terminal fields of this pathway (Di Chiara and Imperato, 1988; Wise, 1996). Different terminal regions are thought to be involved in the different aspects of addictive behavior. The nucleus accumbens is thought to be involved in the mediation of the acute reinforcing effects of drugs (Di Chiara, 2002; Volkow et al., 2002) whereas changes in the prefrontal cortex, orbitofrontal cortex, and anterior cingulate are related to the decreases in inhibitory control and hyper-responsiveness to drug-related cues (Kalivas and Volkow, 2005; Goldstein and Volkow, 2011). The amygdaloid complex and hippocampus play an important role in conditioning and learning associations between drugs and drug-related stimuli (Fuchs et al., 2005, 2007; See, 2005; Rogers and See, 2007). More recently, attention has been given to the role of neuropeptides in modulating the mesocorticolimbic system, including the neuropeptide orexin.

The function of a particular orexin neuron appears to depend on the location of the cell body; neurons from dorsomedial hypothalamic areas and perifornical hypothalamus are reportedly associated with arousal and stress, while orexin neurons from $\mathrm{LH}$ are suggested to be associated with reward-seeking processes for both natural and drug rewards (Harris and Aston-Jones, 2006). Moreover, other studies with varying drug challenges also support the notion that the hypothalamic orexin neurons are functionally heterogeneous (Fadel and Deutch, 2002; McPherson et al., 2007). Orexinergic neurons send projections to the ventral tegmental area (VTA) and nucleus accumbens (Fadel and Deutch, 2002). With regards the VTA, both dopaminergic and GABAergic neurons appear to be innervated, albeit somewhat sparsely (Balcita Pedicino and Sesack, 2007). Nevertheless, evidence is accruing for direct orexinergic input onto VTA dopaminergic cells that innervate the prefrontal cortex and nucleus accumbens (Vittoz et al., 2008). While the VTA receives input from both medial and lateral orexinergic neurons (González et al., 2012), in terms of opiate dependence, orexin inputs onto caudal VTA cells are implicated (Richardson and Aston-Jones, 2012). Thus, given the innervations of mesolimbic regions by orexin and the presence of orexin receptors in these nuclei, a framework exists to suggest a potential role in mediating the rewarding effects of drugs of abuse including alcohol. The main goal of this present review is to focus on orexins and alcohol, and to provide an update on this rapidly developing field (Lawrence, 2010).

In electrophysiological studies on brain slices bath application of orexin-A potentiates NMDA currents in VTA neurons, while orexin-B potentiates both NMDA and AMPA currents (Borgland et al., 2006). When both orexin peptides are applied, the effect is greater than seen with orexin-B alone, suggesting that both peptides exert actions through distinct receptors, signal transduction pathways and/or cellular targets (Borgland et al., 2008). Orexins caused an increased in firing frequency, burst firing, or no change in firing in different groups of A10 dopamine and non-dopamine neurons in the VTA (Korotkova et al., 2003). Microdialysis studies showed increased dopamine and metabolite levels in nucleus accumbens after intra-VTA microinjection of orexin-A and orexin-B (Narita et al., 2006).

\section{OREXINS AND ALCOHOL SELF-ADMINISTRATION}

There is no apparent difference in the density of expression of the mRNA encoding pre-proorexin in the hypothalamus of alcoholpreferring $\mathrm{P}$ rats compared to non-preferring NP rats (Lawrence et al., 2006). It has been known for some time that High saccharin intake (HiS) rats voluntarily consume more ethanol compared to Low Saccharin intake (LoS) rats, as well as showing other addiction-prone behaviors (Dess et al., 1998). More recently, it has been demonstrated that HiS rats possess a higher number of positive orexin cells in the LH and PFA than LoS rats (Holtz et al., 2012). Rats with high novelty-induced activity show both high ethanol consumption and elevated orexin mRNA expression 
in the perifornical hypothalamus, while expression of orexin was reduced in rats with high triglycerides despite similar ethanol intake (Barson et al., 2012). Therefore, while there is no clear link between orexin expression and alcohol preference per se, chronic ethanol consumption does alter the expression of pre-proorexin mRNA in the LH of rats (Lawrence et al., 2006; Morganstern et al., 2010).

The operant self-administration procedure is a widely accepted animal model to study drug reinforcement and drug-seeking. Evidence for a role of orexins in the reinforcing properties of alcohol was established by the observation that OX1R-selective antagonist SB 334867 attenuated operant self-administration of ethanol by Indiana-preferring (iP) rats (Lawrence et al., 2006). Subsequently, a similar effect was demonstrated in Long-Evans rats which was specific to ethanol, as sucrose self-administration was not affected (Richards et al., 2008). This contrasts with another study which showed that $30 \mathrm{mg} / \mathrm{kg}$ of SB 334867 decreased responding for both sucrose pellets and ethanol in rats (Cason et al., 2010). More recently we have shown that while $5 \mathrm{mg} / \mathrm{kg}$ of SB 334867 can attenuate selfadministration of both sucrose and ethanol solutions, there is a significantly greater effect for ethanol compared to sucrose (Jupp et al., 2011a). Moreover, we showed a greater role for OX1R in the motivational properties of ethanol, as the same dose of SB 334867 attenuated responding on a progressive ratio schedule for ethanol but not sucrose (Jupp et al., 2011a). The apparently contradictory effects observed with natural reward may relate to differences in the reinforcement schedule used in each study (FR1 vs. FR3 vs. PR), and/or the doses of compounds used. Thus, attenuation of sucrose self-administration occurs at higher doses of SB 334867 (Cason et al., 2010), where selectivity between OX1R and OX2R may be reduced.

Collectively however, these data point to a role for the OX1R in the rewarding and motivational properties of ethanol. Importantly however, a recent study found no impact of OX1R antagonism on ethanol self-administration by Wistar rats with the OX1R antagonist SB-408124 (Shoblock et al., 2011). The level of ethanol self-administration by the Wistar rats in this study was relatively low compared to alcohol-preferring strains. Hence, the authors raise the possibility that activity at OX1R is only recruited during high levels of ethanol intake, or only involved during high motivation to consume ethanol. This hypothesis is supported by the observation that SB 334867 reduces alcohol consumption and preference in Sprague-Dawley rats with a high baseline preference for alcohol while having no effect on those with a low baseline preference (Moorman and AstonJones, 2009). In addition, OX1R activation has been linked to high effort work for extremely salient rewards (Borgland et al., 2009).

Nevertheless, a recent study has implicated the relatively less-studied OX2R in ethanol reward. The OX2R antagonist, JNJ 10397049, reduced ethanol, but not saccharin, selfadministration after systemic administration (Shoblock et al., 2011). Indeed, it has been suggested that studies with relatively high doses of "selective" OX1R antagonists may in fact be difficult to interpret as solely acting through OX1R due to loss of selectivity in vivo (e.g., Shoblock et al., 2011; Gotter et al.,
2012). In this regard however, as we canvassed in a recent study from our lab (Jupp et al., 2011a), SB 334867 can reduce alcohol self-administration in rats at doses $(5 \mathrm{mg} / \mathrm{kg}$ ip) where OX1R selectivity is retained. On balance, it appears possible that both OX1 and OX2 may play a role in mediating the reinforcing properties of alcohol (and other drugs). It would be worth addressing whether both OX1R and OX2R are implicated in natural and drug rewards more fully. This is now a real possibility with commercially available antagonists for OX1R and OX2R. In this regard, two highly selective compounds namely GSK1059865 (OX1R) and JNJ1037049 (OX2R) have been assessed in conjunction with fMRI in rat brain after an acute amphetamine challenge (Gozzi et al., 2011). The findings suggested that the OX2R effect was predominantly cortical (arousal) while the OX1R effect was predominantly subcortical striatal (reward and goal-directed behaviors). Importantly, these conclusions do not preclude a potential cortical action of OX1R. Such functionally topography may relate to suggestions that orexin projections from the LH control drugseeking behavior through activation of reward pathways and perifornical-dorsomedial areas of hypothalamus control interface arousal and the stress pathways (Harris and Aston-Jones, 2006). Future studies will undoubtedly address the issue of the precise functional interplay between medial and lateral orexinergic populations.

The above-mentioned data relate to studies using systemic administration of drugs to manipulate the orexin system. While of value, they do not provide evidence for anatomic loci of action where orexins may be acting in the brain to regulate self-administration of alcohol. Microinjections of orexin-A into the paraventricular nucleus and LH increase ethanol selfadministration, but not food or water consumption in SpragueDawley rats (Schneider et al., 2007). In contrast, intra-nucleus accumbens microinjections of orexin-A had no effect on ethanol intake (Schneider et al., 2007). More recently, intra-LH injections of NMDA stimulate both ethanol intake and expression of orexin in rats (Chen et al., 2012). Therefore, while hypothalamic sites where orexins regulate ethanol intake have been identified, there is still a need to fully evaluate potential extra-hypothalamic sites of action.

\section{OREXINS IN ALCOHOL RELAPSE/REINSTATEMENT}

The extinction-reinstatement paradigm is a commonly used animal model of relapse and is used to investigate the neurobiology underlying drug-seeking behavior (Stretch et al., 1971; Davis and Smith, 1976; De Wit and Stewart, 1981). In 2005 it was reported that intracerebroventricular administration of orexinA reinstated extinguished responding on a cocaine-paired lever in rats (Boutrel et al., 2005; Wang et al., 2009). The same has also been found for nicotine-seeking behavior in mice (PlazaZabala et al., 2010). SB 334867 attenuates reinstatement induced by a cocaine- and heroin-related stimulus, without affecting that induced by a stimulus conditioned to a conventional reinforcer (Smith et al., 2009; Martin-Fardon et al., 2010; Smith and AstonJones, 2012). A similar result is found when drug-seeking is assessed after 1 day or 2 weeks of abstinence (without extinction) or following extinction of cocaine-seeking in a different context (Smith et al., 2010). Zhou et al. (2012) showed that SB 334867 
regulated cue-induced reinstatement of cocaine-seeking in male, but not female, rats.

In the alcohol field, Lawrence et al. (2006) provided the first evidence linking the orexin system in cue-induced reinstatement of alcohol-seeking. Shortly afterwards these functional data were supported by demonstration that cue-induced reinstatement of alcohol-seeking was associated with activation of orexin-containing neurons (Dayas et al., 2008). Also, in the renewal paradigm of alcohol-seeking there is a significant positive correlation between the activation of orexin neurons and relapse responding on the "active" nose-poke (Hamlin et al., 2007). Subsequently this evidence has been expanded to include the observation that SB 334867 abolishes cue-induced reinstatement of alcohol-seeking both immediately after extinction as well as after an extended period of abstinence following extinction (Jupp et al., 2011b). Collectively, these data suggest that despite extinction and long-term abstinence, the orexinergic system is seemingly still involved in the integration of the salience of cues that previously signaled the availability of ethanol. The latter study included an examination of the pattern of neuronal activation following immediate vs. delayed reinstatement. Thus, the putative anatomic loci where SB-334867 may be acting (directly or indirectly) to regulate relapse-like alcohol-seeking seemingly includes prefrontal cortical structures. Intriguingly, the putative anatomic loci where SB 334867 may act (directly or indirectly) to regulate relapse-like alcohol-seeking apparently shifts from orbitofrontal/medial prefrontal cortex, accumbens core and basolateral amygdala (BLA) following immediate reinstatement to primarily a cortical locus following delayed reinstatement. These findings collectively suggest that the circuitry through which orexin impacts upon alcohol-seeking driven by exposure to cues may change over time. Further studies, including functional mapping, are required to determine the precise loci where OX1R may regulate cue-induced alcohol-seeking, including cortical sites and subcortical targets, such as the VTA which has recently been implicated in cue-driven cocaine-seeking (James et al., 2011). Reversible inactivation of LH prevented cue-induced reinstatement of beer and sucrose-seeking rats (Marchant et al., 2009). Using the retrograde neuronal tracer combined with Fos activation method, recruitment of LH-projecting neurons from nucleus accumbens shell during reinstatement was demonstrated (Marchant et al., 2009).

Dhaher et al. (2010) reported that SB 334867 prevented the increase of ethanol consumption observed on relapse following abstinence, but did not have any effect on Pavlovian spontaneous recovery of alcohol-seeking after 2 weeks abstinence. Nevertheless, the same OX1R antagonist reduces stress-induced reinstatement to alcohol or sucrose-seeking by yohimbine (Richards et al., 2008); or the cue-induced reinstatement of alcohol seeking facilitated by intra-lateral hypothalamic injection of neuropeptides S (NPS) in rats (Cannella et al., 2009). As is the case with ethanol consumption, recent studies have found that SB 334867 is more effective at reducing reinstatement of alcohol-seeking compared to that for a natural reward (MartinFardon and Weiss, 2012). Interestingly, inhibition of hypothalamic peptides, including orexin neurons, by projections from nucleus accumbens shell has been implicated in the extinction of alcohol-seeking behavior (Millan et al., 2010), suggesting a possible role for orexins in extinction.

\section{OREXINS IN ALCOHOL CONDITIONED PLACE PREFERENCE}

A study utilizing the CPP paradigm provided the first evidence for a role for the orexin neurons of the LH in reward and reward-seeking. Conditioned animals which show a preference for a reward-paired chamber (with food, morphine, or cocaine) display increased Fos expression in lateral hypothalamic orexin cells (Harris et al., 2005). It was demonstrated that neurons that project from rostral lateral septum to $\mathrm{LH}$ are activated in proportion to cocaine-induced CPP, and the inhibition of lateral septum neurons blocked Fos expression in orexin cells in the LH (Sartor and Aston-Jones, 2012). Studies involving functional topography of orexin projections to VTA showed that this region is a significant target of orexin action (Richardson and Aston-Jones, 2012). Administration of the OX1R antagonist SB 334867 intra-VTA was found to reduce morphine CPP (Narita et al., 2006) while administration of morphine systemically or orexin-A into the VTA reinstated this CPP (Harris et al., 2005). In addition, microinjection of Y4 receptor agonist, $\mathrm{rPP}$ (rat pancreatic polypeptide), into the $\mathrm{LH}$ reinstated the extinguished morphine CPP which could be blocked by previous OX1R antagonist treatment (Harris et al., 2005). Subsequent studies have further supported a role for OX1R in opiate place preference (Sharf et al., 2010).

Alcohol CPP studies are equivocal at this stage and it appears that there may be a differential role for OX1R and OX2R in the conditioned rewarding effects of ethanol. OX1R antagonism by SB 334867 attenuated a weak CPP to ethanol in DBA mice; however, when a different protocol which resulted in a strong CPP was utilized SB 334867 had no effect (Voorhees and Cunningham, 2011). More recently, a different OX1 receptor antagonist SB-408124 was found to have no effect on the acquisition or expression of an ethanol-induced CPP in DBA mice (Shoblock et al., 2011). These authors found that the OX2R antagonist JNJ 10397049 attenuated the acquisition, expression, and reinstatement of an ethanol-induced CPP (Shoblock et al., 2011).

\section{OREXINS AND BEHAVIORAL SENSITIZATION}

Behavioral sensitization has been proposed to occur as a result of changes in the neural circuits that regulate the attribution of incentive salience to stimuli (Robinson and Berridge, 2008). Intracerebroventricular injections of orexin A or orexin $B$ increase locomotor activity in mice (Narita et al., 2006). Both systemic and intra-VTA administration of SB 334867 blocks the development of behavioral sensitization to cocaine in rats (Borgland et al., 2006). Importantly, intra-VTA SB 334867 itself does not alter locomotor activity at doses that regulate cocaineseeking (James et al., 2011). In contrast to cocaine, SB 334867 had no effect on either acute or sensitized responses to morphine (Sharf et al., 2010). OX1R antagonism decreases ethanolinduced locomotor activity in mice, but not spontaneous activity in mice (Voorhees and Cunningham, 2011) or rats (Richards et al., 2008). In addition, recent data suggest that OX2R antagonism can attenuate ethanol-induced locomotor activity in mice (Shoblock et al., 2011). As yet, a role for orexin in behavioral 
sensitization to ethanol has not been thoroughly examined. However, pre-proorexin knockout mice showed intact acute locomotor responses and behavioral sensitization to morphine (Sharf et al., 2010).

\section{OREXINS AND MOTOR FUNCTION}

When combined with ethanol, Almorexant, a dual orexin receptor antagonist, did not interfere in rotarod performance and grip strength, showing no action in motor coordination (Steiner et al., 2011). Moreover, this study also suggested that Almorexant has no effect upon ethanol-induced sedation. In humans, there is no potentiation of alcohol impairment by Almorexant (Hoch et al., 2012). In rats, orexin-A or -B given icv reduced the hypnotic effects of ethanol (Jia et al., 2011). In a prenatal alcohol exposure procedure, it was observed that rats which received alcohol intragastrically twice daily on postnatal days PD 4-9, and were then treated with SB 334867 daily on PD 12-14, presented lower levels of activity upon test than rats who had received vehicle on PD 12-14 (Stettner et al., 2011). This finding implicates the orexin system in the persistent hyperactivity observed following prenatal alcohol exposure. Intriguingly, prenatal alcohol exposure (via dams gavaged from E9 to parturition with 1 or $3 \mathrm{~g} / \mathrm{kg}$ of ethanol) stimulates neurogenesis, including that of orexinergic neurons, which may contribute to altered consumption patterns in exposed offspring (Chang et al., 2012).

\section{OREXINS AND WITHDRAWAL}

Somatic signals of nicotine-induced withdrawal were attenuated with OX1R antagonism or in pre-proorexin knockout mice. In parallel, nicotine withdrawal-induced Fos expression in the $\mathrm{DMH}$ /perifornical region and the PVN was attenuated by pretreatment with SB 334867 (Plaza-Zabala et al., 2012). In terms of ethanol, data from alcohol-dependent subjects implicates orexin in affective dysregulation that accompanies withdrawal (Von Der Goltz et al., 2011). Indeed, there is a significant association between orexin A levels and severity of withdrawal scores (Bayerlein et al., 2011).

\section{FUTURE DIRECTIONS}

In this review we have summarized recent studies focusing on implications of the orexin system in alcohol use and abuse. There are still numerous questions that remain to be answered: for example, defining the anatomic loci for putative actions of OX1R versus $\mathrm{OX} 2 \mathrm{R}$ in regulating alcohol use, and evaluating the possibility of dual OX1/OX2R antagonists as potential pharmacotherapeutics. In relation to medication development, assessing the functioning and responsivity of orexin systems in states of alcohol dependence are also warranted. Another issue is elucidating the precise role orexins play in the conditioned reinforcing effects of alcohol across different species. From a neurobiological perspective, the integration of orexin-containing neurons into the circuitries underpinning many of the behaviors discussed requires more thorough attention. Related to this point is a pressing need to delineate the interactions between orexins and other peptides, such as NPS (Cannella et al., 2009), galanin (Karatayev et al., 2010) plus undoubtedly others, and non-peptides, such as histamine (Jia et al., 2011). While much of the data to date address the issue of a direct role for orexins in alcohol use and relapse, the field should also be cognizant of the evidence of a possible role for orexins in alcohol withdrawal. As mentioned above, recent human studies suggest that the more severe alcohol withdrawal symptoms are, the greater reduction in orexin-A expression is observed, at least in lymphocytes (Bayerlein et al., 2011). This finding, including observations on orexin A promoter methylation (Bayerlein et al., 2011), suggest the potential for involvement of orexins in aspects of the withdrawal syndrome following chronic alcohol, and possibly other drug, use. Naturally, this supposition is based upon the assumption that epigenetic alterations in lymphocytes are mirrored in neurons, which remains to be clarified. Nevertheless, our laboratory has recently demonstrated that even following protracted abstinence, orexin signaling is activated upon re-presentation of cues previously paired with alcohol availability. Therefore, orexins may actually exert multiple roles in relation to alcohol use and abuse, ranging from consumption, motivational strength, withdrawal through to relapse. Given the various lines of evidence for these factors presented within this review, it is clear that substantial further research is required to confirm or refute these hypotheses.

\section{ACKNOWLEDGMENTS}

These studies were supported by a project grant from the NHMRC (Australia) of which Andrew J. Lawrence is a Principal Fellow. Financial support from the Pratt/Besen Foundations and the Victorian Government's Operational Infrastructure Support Program are gratefully acknowledged. Andrezza K. Kim was supported by Conselho Nacional de Desenvolvimento Cientifico e Tecnologico (CNPq)_Brazil.

\section{REFERENCES}

Allen, G. V., and Cechetto, D. F. (1992). Functional and anatomical organization of cardiovascular pressor and depressor sites in the lateral hypothalamic area: I. Descending projections. J. Comp. Neurol. 315, 313-332.

Aston-Jones, G., Smith, R. J., Moorman, D. E., and Richardson, K. A. (2009). Role of lateral hypothalamic orexin neurons in reward processing and addiction.
Neuropharmacology 56(Suppl. 1), 112-121.

Balcita Pedicino, J., and Sesack, S. (2007). Orexin axons in the rat ventral tegmental area synapse infrequently onto dopamine and gamma-aminobutyric acid neurons. J. Comp. Neurol. 503, 668-684.

Barson, J., Fagan, S., Chang, G.-Q., and Leibowitz, S. (2012). Neurochemical heterogeneity of rats predicted by different measures to be high ethanol consumers. Alcohol. Clin. Exp. Res. PMID: 22725682. [Epub ahead of print].

Bayerlein, K., Kraus, T., Leinonen, I., Pilniok, D., Rotter, A., Hofner, B. et al. (2011). Orexin A expression and promoter methylation in patients with alcohol dependence comparing acute and protracted withdrawal. Alcohol 45, 541-547.

Bergman, J. M., Roecker, A. J., Mercer, S. P., Bednar, R. A., Reiss, D. R., Ransom, R. W., et al. (2008). Proline bis-amides as potent dual orexin receptor antagonists. Bioorg. Med. Chem. Lett. 18, 1425-1430.

Borgland, S. L., Chang, S. J., Bowers, M. S., Thompson, J. L., Vittoz, N. Floresco, S. B., et al. (2009). Orexin A/hypocretin-1 selectively promotes motivation for positive reinforcers. J. Neurosci. 29, 11215-11225.

Borgland, S. L., Storm, E., and Bonci, A. (2008). Orexin B/hypocretin 2 increases glutamatergic transmission to ventral tegmental area 
neurons. Eur. J. Neurosci. 28, 1545-1556.

Borgland, S. L., Taha, S. A., Sarti, F., Fields, H. L., and Bonci, A. (2006). Orexin A in the VTA is critical for the induction of synaptic plasticity and behavioral sensitization to cocaine. Neuron 49, 589-601.

Boss, C., Brisbare-Roch, C., and Jenck, F. (2009). Biomedical application of orexin/hypocretin receptor ligands in neuroscience. J. Med. Chem. 52, 891-903.

Bourgin, P., Huitron-Resendiz, S., Spier, A. D., Fabre, V., Morte, B., Criado, J. R., et al. (2000). Hypocretin-1 modulates rapid eye movement sleep through activation of locus coeruleus neurons. J. Neurosci. 20, 7760-7765.

Boutrel, B., Kenny, P. J., Specio, S. E., Martin-Fardon, R., Markou, A., Koob, G. F., et al. (2005). Role for hypocretin in mediating stressinduced reinstatement of cocaineseeking behavior. Proc. Natl. Acad. Sci. U.S.A. 102, 19168-19173.

Brisbare-Roch, C., Dingemanse, J., Koberstein, R., Hoever, P., Aissaoui, H., Flores, S., et al. (2007). Promotion of sleep by targeting the orexin system in rats, dogs and humans. Nat. Med. 13, 150-155.

Broberger, C., De Lecea, L., Sutcliffe, J. G., and Hokfelt, T. (1998). Hypocretin/orexin- and melaninconcentrating hormone-expressing cells form distinct populations in the rodent lateral hypothalamus: relationship to the neuropeptide $\mathrm{Y}$ and agouti gene-related protein systems. J. Comp. Neurol. 402, 460-474.

Brown, R. E., Sergeeva, O., Eriksson, K. S., and Haas, H. L. (2001). Orexin A excites serotonergic neurons in the dorsal raphe nucleus of the rat. Neuropharmacology 40, 457-459.

Brown, R. E., Sergeeva, O. A., Eriksson, K. S., and Haas, H. L. (2002). Convergent excitation of dorsal raphe serotonin neurons by multiple arousal systems (orexin/hypocretin, histamine and noradrenaline). J. Neurosci. 22, 8850-8859.

Burlet, S., Tyler, C. J., and Leonard, C. S. (2002). Direct and indirect excitation of laterodorsal tegmental neurons by Hypocretin/Orexin peptides: implications for wakefulness and narcolepsy. J. Neurosci. 22, 2862-2872.

Cannella, N., Economidou, D., Kallupi, M., Stopponi, S., Heilig, M., Massi, M., et al. (2009). Persistent increase of alcohol-seeking evoked by neuropeptide S: an effect mediated by the hypothalamic hypocretin system. Neuropsychopharmacology 34, 2125-2134.

Cason, A. M., Smith, R. J., TahsiliFahadan, P., Moorman, D. E., Sartor, G. C., and Aston-Jones, G. (2010). Role of orexin/hypocretin in reward-seeking and addiction: implications for obesity. Physiol. Behav. 100, 419-428.

Chang, G. Q., Karatayev, O., Liang, S. C., Barson, J. R., and Leibowitz, S. F. (2012). Prenatal ethanol exposure stimulates neurogenesis in hypothalamic and limbic peptide systems: possible mechanism for offspring ethanol overconsumption. Neuroscience PMID: 22742906. [Epub ahead of print].

Chen, Y. W., Barson, J. R., Chen, A., Hoebel, B. G., and Leibowitz, S. F. (2012). Glutamatergic input to the lateral hypothalamus stimulates ethanol intake: role of orexin and melanin-concentrating hormone. Alcohol Clin. Exp. Res. PMID: 22823322. [Epub ahead of print].

Cox, C. D., McGaughey, G. B., Bogusky, M. J., Whitman, D. B., Ball, R. G., Winrow, C. J., et al. (2009). Conformational analysis of $\mathrm{N}$, N-disubstituted-1, 4-diazepane orexin receptor antagonists and implications for receptor binding. Bioorg. Med. Chem. Lett. 19, 2997-3001.

Date, Y., Ueta, Y., Yamashita, H., Yamaguchi, H., Matsukura, S., Kangawa, K., et al. (1999). Orexins, orexigenic hypothalamic peptides, interact with autonomic, neuroendocrine and neuroregulatory systems. Proc. Natl. Acad. Sci. U.S.A. 96, 748-753.

Davis, W. M., and Smith, S. G. (1976). Role of conditioned reinforcers in the initiation, maintenance and extinction of drug-seeking behavior. Pavlov. J. Biol. Sci. 11, 222-236.

Dayas, C. V., McGranahan, T. M., Martin-Fardon, R., and Weiss, F. (2008). Stimuli linked to ethanol availability activate hypothalamic CART and orexin neurons in a reinstatement model of relapse. Biol. Psychiatry 63, 152-157.

De Lecea, L., Kilduff, T. S., Peyron, C., Gao, X., Foye, P. E., Danielson, P. E., et al. (1998). The hypocretins: hypothalamus-specific peptides with neuroexcitatory activity. Proc. Natl. Acad. Sci. U.S.A. 95 322-327.

De Wit, H., and Stewart, J. (1981). Reinstatement of cocainereinforced responding in the rat. Psychopharmacology (Berl.) 75, 134-143.
Dess, N. K., Badia-Elder, N. E., Thiele, T. E., Kiefer, S. W., and Blizard D. A. (1998). Ethanol consumption in rats selectively bred for differential saccharin intake. Alcohol 16, 275-278.

Dhaher, R., Hauser, S. R., Getachew, B. Bell, R. L., McBride, W. J., McKinzie, D. L., et al. (2010). The Orexin1 receptor antagonist SB-334867 reduces alcohol relapse drinking, but not alcohol-seeking, in alcoholpreferring (P) rats. J. Addict. Med. 4 , 153-159.

Di Chiara, G., and Imperato, A. (1988). Drugs abused by humans preferentially increase synaptic dopamine concentrations in the mesolimbic system of freely moving rats. Proc. Natl. Acad. Sci. U.S.A. 85, 5274-5278.

Di Chiara, G. (2002). From rats to humans and return: testing addiction hypotheses by combined PET imaging and self-reported measures of psychostimulant effects. Commentary on Volkow et al. 'Role of dopamine in drug reinforcement and addiction in humans: results from imaging studies'. Behav. Pharmacol. 13, 371-377.

Dugovic, C., Shelton, J. E., Aluisio, L. E., Fraser, I. C., Jiang, X., Sutton, S. W., et al. (2009). Blockade of orexin-1 receptors attenuates orexin-2 receptor antagonisminduced sleep promotion in the rat. J. Pharmacol. Exp. Ther. 330, 142-151.

Elias, C. F., Saper, C. B., Maratos-Flier, E., Tritos, N. A., Lee, C., Kelly, J., et al. (1998). Chemically defined projections linking the mediobasal hypothalamus and the lateral hypothalamic area. J. Comp. Neurol. 402, 442-459.

Fadel, J., and Deutch, A. Y. (2002). Anatomical substrates of orexindopamine interactions: lateral hypothalamic projections to the ventral tegmental area. Neuroscience 111, 379-387

Fuchs, R. A., Evans, K. A., Ledford, C. C., Parker, M. P., Case, J. M., Mehta, R. H., et al. (2005). The role of the dorsomedial prefrontal cortex, basolateral amygdala, and dorsal hippocampus in contextual reinstatement of cocaine seeking in rats. Neuropsychopharmacology 30 , 296-309.

Fuchs, R. A., Eaddy, J. L., Su, Z. I., and Bell, G. H. (2007). Interactions of the basolateral amygdala with the dorsal hippocampus and dorsomedial prefrontal cortex regulate drug context-induced reinstatement of cocaine-seeking in rats. Eur. J. Neurosci. 26, 487-498.
Goldstein, R. Z., and Volkow, N. D. (2011). Dysfunction of the prefrontal cortex in addiction: neuroimaging findings and clinical implications. Nat. Rev. Neurosci. 12, 652-669.

González, J. A., Jensen, L., Fugger, L., and Burdakov, D. (2012). Convergent inputs from electrically and topographically distinct orexin cells to locus coeruleus and ventral tegmental area. Eur. J. Neurosci. 35, 1426-1432.

Gotter, A. L., Roecker, A. J., Hargreaves, R., Coleman, P. J., Winrow, C. J., and Renger, J. J. (2012). Orexin receptors as therapeutic drug targets. Prog. Brain Res. 198, 163-188.

Gozzi, A., Turrini, G., Piccoli, L., Massagrande, M., Amantini, D., Antolini, M., et al. (2011). Functional magnetic resonance imaging reveals different neural substrates for the effects of orexin-1 and orexin-2 receptor antagonists. PLOS ONE 6:e16406. doi: 10.1371/journal.pone.0016406

Hagan, J. J., Leslie, R. A., Patel, S., Evans, M. L., Wattam, T. A., Holmes, S., et al. (1999). Orexin A activates locus coeruleus cell firing and increases arousal in the rat. Proc. Natl. Acad. Sci. U.S.A. 96 10911-10916.

Hamlin, A. S., Newby, J., and McNally, G. P. (2007). The neural correlates and role of D1 dopamine receptors in renewal of extinguished alcohol-seeking. Neuroscience 146, 525-536.

Harris, G. C., and Aston-Jones, G. (2006). Arousal and reward: a dichotomy in orexin function. Trends Neurosci. 29, 571-577.

Harris, G. C., Wimmer, M., and AstonJones, G. (2005). A role for lateral hypothalamic orexin neurons in reward seeking. Nature 437, 556-559.

Hoch, M., Hay, J., Hoever, P., De Kam, M., Te Beek, E., Van Gerven, J. M. A., et al. (2012). Dual orexin receptor antagonism by almorexant does not potentiate impairing effects of alcohol in humans. Eur. Neuropsychopharmacol. PMID: 22658401. [Epub ahead of print].

Holtz, N. A., Zlebnik, N. E., and Carroll, M. E. (2012). Differential orexin/hypocretin expression in addiction-prone and -resistant rats selectively bred for high (HiS) and low (LoS) saccharin intake. Neurosci. Lett. 522, 12-15.

Horvath, T. L., Peyron, C., Diano, S. Ivanov, A., Aston-Jones, G., Kilduff, T. S., et al. (1999). Hypocretin (orexin) activation and synaptic innervation of the locus coeruleus 
noradrenergic system. J. Comp. Neurol. 415, 145-159.

James, M. H., Charnley, J. L., Levi, E. M., Jones, E., Yeoh, J. W., Smith, D. W., et al. (2011). Orexin1 receptor signalling within the ventral tegmental area, but not the paraventricular thalamus, is critical to regulating cue-induced reinstatement of cocaine-seeking. Int. J. Neuropsychopharmacol. 14, 684-690.

Jaszberenyi, M., Bujdoso, E., Pataki, I., and Telegdy, G. (2000). Effects of orexins on the hypothalamicpituitary-adrenal system. $J$. Neuroendocrinol. 12, 1174-1178.

Jia, X., Yan, J., Xia, J., Xiong, J., Wang, T., Chen, Y., et al. (2011). Arousal effects of orexin A on acute alcohol intoxication-induced coma in rats. Neuropharmacology 62, 775-783.

Jupp, B., Krivdic, B., Krstew, E., and Lawrence, A. J. (2011a). The orexin receptor antagonist SB-334867 dissociates the motivational properties of alcohol and sucrose in rats. Brain Res. 1391, 54-59.

Jupp, B., Krstew, E., Dezsi, G., and Lawrence, A. J. (2011b). Discrete cue-conditioned alcohol-seeking after protracted abstinence: pattern of neural activation and involvement of orexin receptors. $\mathrm{Br}$. J. Pharmacol. 162, 880-889.

Kalivas, P. W., and Volkow, N. D. (2005). The neural basis of addiction: a pathology of motivation and choice. Am. J. Psychiatry 162, 1403-1413.

Karatayev, O., Baylan, J., Weed, V., Chang, S., Wynick, D., and Leibowitz, S. F. (2010). Galanin knockout mice show disturbances in ethanol consumption and expression of hypothalamic peptides that stimulate ethanol intake. Alcohol. Clin. Exp. Res. 34, 72-80.

Korotkova, T. M., Sergeeva, O. A., Eriksson, K. S., Haas, H. L., and Brown, R. E. (2003). Excitation of ventral tegmental area dopaminergic and nondopaminergic neurons by orexins/hypocretins. J. Neurosci. 23, 7-11.

Kuru, M., Ueta, Y., Serino, R., Nakazato, M., Yamamoto, Y., Shibuya, I., et al. (2000). Centrally administered orexin/hypocretin activates HPA axis in rats. Neuroreport 11, 1977-1980.

Langmead, C. J., Jerman, J. C., Brough, S. J., Scott, C., Porter, R. A., and Herdon, H. J. (2004). Characterisation of the binding of [3H]-SB-674042, a novel nonpeptide antagonist, to the human orexin-1 receptor. Br. J. Pharmacol. $141,340-346$
Lawrence, A. J. (2010). Regulation of alcohol-seeking by orexin (hypocretin) neurons. Brain Res. 1314, 124-129.

Lawrence, A. J., Cowen, M. S., Yang, H. J., Chen, F., and Oldfield, B. (2006). The orexin system regulates alcoholseeking in rats. Br. J. Pharmacol. 148, 752-759.

Lovinger, D. M. (1999). 5-HT3 receptors and the neural actions of alcohols: an increasingly exciting topic. Neurochem. Int. 35, 125-130.

Lovinger, D. M., White, G., and Weight, F. F. (1989). Ethanol inhibits NMDA-activated ion current in hippocampal neurons. Science 243, 1721-1724.

Malherbe, P., Borroni, E., Gobbi, L., Knust, H., Nettekoven, M., Pinard, E., et al. (2009a). Biochemical and behavioural characterization of EMPA, a novel high-affinity, selective antagonist for the $\mathrm{OX}(2)$ receptor. Br. J. Pharmacol. 156, 1326-1341.

Malherbe, P., Borroni, E., Pinard, E., Wettstein, J. G., and Knoflach, F. (2009b). Biochemical and electrophysiological characterization of almorexant, a dual orexin 1 receptor $(\mathrm{OX} 1) /$ orexin 2 receptor (OX2) antagonist: comparison with selective OX1 and OX2 antagonists. Mol. Pharmacol. 76, 618-631.

Marchant, N. J., Hamlin, A. S., and McNally, G. P. (2009). Lateral hypothalamus is required for context-induced reinstatement of extinguished reward seeking. J. Neurosci. 29, 1331-1342.

Martin-Fardon, R., and Weiss, F. (2012). N-(2-methyl-6-benz oxazolyl)-N' $-1, \quad 5$-naphthyridin-4yl urea (SB 334867), a hypocretin receptor-1 antagonist, preferentially prevents ethanol seeking: comparison with natural reward seeking. Addict. Biol. PMID: 22830647. [Epub ahead of print].

Martin-Fardon, R., Zorrilla, E. P., Ciccocioppo, R., and Weiss, F. (2010). Role of innate and drug-induced dysregulation of brain stress and arousal systems in addiction: focus on corticotropin-releasing factor, nociceptin/orphanin $\mathrm{FQ}$, and orexin/hypocretin. Brain Res. 1314, 145-161.

McAtee, L. C., Sutton, S. W., Rudolph, D. A., Li, X., Aluisio, L. E., Phuong, V. K., et al. (2004). Novel substituted 4-phenyl-[1,3]dioxanes: potent and selective orexin receptor $2(\mathrm{OX}(2) \mathrm{R})$ antagonists. Bioorg. Med. Chem. Lett. 14, 4225-4229.

McPherson, C. S., Featherby, T., Krstew, E., and Lawrence, A. J. (2007)
Quantification of phosphorylated cAMP-response element-binding protein expression throughout the brain of amphetamine-sensitized rats: activation of hypothalamic orexin A-containing neurons. J. Pharmacol. Exp. Ther. 323, 805-812.

Mihic, S. J. (1999). Acute effects of ethanol on GABAA and glycine receptor function. Neurochem. Int. $35,115-123$.

Millan, E. Z., Furlong, T. M., and McNally, G. P. (2010). Accumbens shell-hypothalamus interactions mediate extinction of alcohol seeking. J. Neurosci. 30, 4626-4635.

Moorman, D. E., and Aston-Jones, G. (2009). Orexin-1 receptor antagonism decreases ethanol consumption and preference selectively in high-ethanol-preferring Sprague-Dawley rats. Alcohol 43, 379-386.

Morganstern, I., Chang, G. Q., Barson, J. R., Ye, Z., Karatayev, O., and Leibowitz, S. F. (2010). Differential effects of acute and chronic ethanol exposure on orexin expression in the perifornical lateral hypothalamus. Alcohol. Clin. Exp. Res. 34 886-896.

Nambu, T., Sakurai, T., Mizukami, K. Hosoya, Y., Yanagisawa, M., and Goto, K. (1999). Distribution of orexin neurons in the adult rat brain. Brain Res. 827, 243-260.

Narahashi, T., Aistrup, G. L., Marszalec, W., and Nagata, K. (1999). Neuronal nicotinic acetylcholine receptors: a new target site of ethanol. Neurochem. Int. 35, 131-141.

Narita, M., Nagumo, Y., Hashimoto, S. Khotib, J., Miyatake, M., Sakurai, T., et al. (2006). Direct involvement of orexinergic systems in the activation of the mesolimbic dopamine pathway and related behaviors induced by morphine. J. Neurosci. 26, 398-405.

Peyron, C., Tighe, D. K., Van Den Pol, A. N., De Lecea, L., Heller, H. C., Sutcliffe, J. G., et al. (1998). Neurons containing hypocretin (orexin) project to multiple neuronal systems. J. Neurosci. 18, 9996-10015.

Plaza-Zabala, A., Flores, A. Maldonado, R., and Berrendero, F. (2012). Hypocretin/orexin signaling in the hypothalamic paraventricular nucleus is essential for the expression of nicotine withdrawal. Biol. Psychiatry 71, 214-223.

Plaza-Zabala, A., Martin-Garcia, E., De Lecea, L., Maldonado, R., and Berrendero, F. (2010). Hypocretins regulate the anxiogenic-like effects of nicotine and induce reinstatement of nicotine-seeking behavior. J. Neurosci. 30, 2300-2310.

Richards, J. K., Simms, J. A., Steensland, P., Taha, S. A., Borgland, S. L., Bonci, A., et al. (2008). Inhibition of orexin-1/hypocretin-1 receptors inhibits yohimbine-induced reinstatement of ethanol and sucrose seeking in Long-Evans rats. Psychopharmacology (Berl.) 199, 109-117.

Richardson, K. A., and Aston-Jones, G. (2012). Lateral hypothalamic orexin/hypocretin neurons that project to ventral tegmental area are differentially activated with morphine preference. J. Neurosci. 32, 3809-3817.

Robinson, T. E., and Berridge, K. C. (2008). Review. The incentive sensitization theory of addiction: some current issues. Philos. Trans. R. Soc. Lond. B Biol. Sci. 363, 3137-3146.

Rodgers, R. J., Halford, J. C., Nunes De Souza, R. L., Canto De Souza, A. L., Piper, D. C., Arch, J. R., et al. (2001). SB-334867, a selective orexin-1 receptor antagonist, enhances behavioural satiety and blocks the hyperphagic effect of orexin-A in rats. Eur. J. Neurosci. 13, 1444-1452.

Rogers, J. L., and See, R. E. (2007) Selective inactivation of the ventral hippocampus attenuates cue-induced and cocaine-primed reinstatement of drug-seeking in rats. Neurobiol. Learn. Mem. 87, 688-692.

Sakurai, T., Amemiya, A., Ishii, M., Matsuzaki, I., Chemelli, R. M., Tanaka, H., et al. (1998). Orexins and orexin receptors: a family of hypothalamic neuropeptides and $G$ protein-coupled receptors that regulate feeding behavior. Cell 92, 573-585.

Sartor, G. C., and Aston-Jones, G. S. (2012). A septal-hypothalamic pathway drives orexin neurons, which is necessary for conditioned cocaine preference. J. Neurosci. 32, 4623-4631.

Scammell, T. E., and Winrow, C. J. (2011). Orexin receptors: pharmacology and therapeutic opportunities. Annu. Rev. Pharmacol. Toxicol. 51, 243-266.

Schneider, E. R., Rada, P., Darby, R. D., Leibowitz, S. F., and Hoebel, B. G. (2007). Orexigenic peptides and alcohol intake: differential effects of orexin, galanin, and ghrelin. Alcohol. Clin. Exp. Res. 31, 1858-1865.

See, R. E. (2005). Neural substrates of cocaine-cue associations that trigger 
relapse. Eur. J. Pharmacol. 526, 140-146.

Sharf, R., Guarnieri, D. J., Taylor, J. R., and Dileone, R. J. (2010). Orexin mediates morphine place preference, but not morphine-induced hyperactivity or sensitization. Brain Res. 1317, 24-32.

Shoblock, J. R., Welty, N., Aluisio, L., Fraser, I., Motley, S. T., Morton, K., et al. (2011). Selective blockade of the orexin-2 receptor attenuates ethanol self-administration, place preference, and reinstatement. Psychopharmacology (Berl.) 215, 191-203.

Smart, D., Sabido-David, C., Brough, S. J., Jewitt, F., Johns, A., Porter, R. A., et al. (2001). SB-334867-A: the first selective orexin-1 receptor antagonist. Br. J. Pharmacol. 132, 1179-1182.

Smith, R. J., and Aston-Jones, G. (2012). Orexin/hypocretin 1 receptor antagonist reduces heroin self-administration and cueinduced heroin seeking. Eur. J. Neurosci. 35, 798-804.

Smith, R. J., See, R. E., and Aston-Jones, G. (2009). Orexin/hypocretin signaling at the orexin 1 receptor regulates cue-elicited cocaine-seeking. Eur. J. Neurosci. 30, 493-503.

Smith, R. J., Tahsili-Fahadan, P., and Aston-Jones, G. (2010). Orexin/hypocretin is necessary for context-driven cocaine-seeking. Neuropharmacology 58, 179-184.

Stanley, B. G., Willett, V. L. 3rd., Donias, H. W., Dee, M. G. 2nd., and Duva, M. A. (1996). Lateral hypothalamic NMDA receptors and glutamate as physiological mediators of eating and weight control. Am. J. Physiol. 270(2 Pt 2), Von Der Goltz, C., Koopmann, R443-R449.

Steiner, M. A., Lecourt, H., Strasser, D. S., Brisbare-Roch, C., and Jenck, F. (2011). Differential effects of the dual orexin receptor antagonist almorexant and the GABA(A)alpha1 receptor modulator zolpidem, alone or combined with ethanol, on motor performance in the rat. Neuropsychopharmacology $36,848-856$

Stettner, G. M., Kubin, L., and Volgin, D. V. (2011). Antagonism of orexin 1 receptors eliminates motor hyperactivity and improves homing response acquisition in juvenile rats exposed to alcohol during early postnatal period. Behav. Brain Res. 221, 324-328.

Stretch, R., Gerber, G. J., and Wood, S. M. (1971). Factors affecting behavior maintained by responsecontingent intravenous infusions of amphetamine in squirrel monkeys. Can. J. Physiol. Pharmacol. 49, 581-589.

Van Den Pol, A. N. (1999). Hypothalamic hypocretin (orexin): robust innervation of the spinal cord. J. Neurosci. 19, 3171-3182.

Vittoz, N., Schmeichel, B., and Berridge, C. (2008). Hypocretin/ orexin preferentially activates caudomedial ventral tegmental area dopamine neurons. Eur. J. Neurosci. 28, 1629-1640.

Volkow, N. D., Fowler, J. S., and Wang, G. J. (2002). Role of dopamine in drug reinforcement and addiction in humans: results from imaging studies. Behav. Pharmacol. 13, 355-366.
A., Dinter, C., Richter, A. Grosshans, M., Fink, T., et al. (2011). Involvement of orexin in the regulation of stress, depression and reward in alcohol dependence. Horm. Behav. 60, 644-650.

Voorhees, C. M., and Cunningham, C. L. (2011). Involvement of the orexin/hypocretin system in ethanol conditioned place preference. Psychopharmacology (Berl.) 214, 805-818.

WHO. (2011). Global Status Report on Alcohol and Health. Geneva: WHO Library Cataloguing-in-Publication Data.

Wang, B., You, Z. B., and Wise, R. A. (2009). Reinstatement of cocaine seeking by hypocretin (orexin) in the ventral tegmental area: independence from the local corticotropin-releasing factor network. Biol. Psychiatry 65, 857-862.

Whitman, D. B., Cox, C. D., Breslin, M. J., Brashear, K. M., Schreier, J. D., Bogusky, M. J., et al. (2009). Discovery of a potent, CNS-penetrant orexin receptor antagonist based on an n, n-disubstituted-1, 4-diazepane scaffold that promotes sleep in rats. ChemMedChem 4, 1069-1074.

Winrow, C. J., Tanis, K. Q., Reiss, D. R., Rigby, A. M., Uslaner, J. M., Uebele, V. N., et al. (2010). Orexin receptor antagonism prevents transcriptional and behavioral plasticity resulting from stimulant exposure. Neuropharmacology 58, 185-194.

Wise, R. A. (1996). Neurobiology of addiction. Curr. Opin. Neurobiol. 6 , 243-251.
Zhou, L., Ghee, S. M., Chan, C., Lin, L., Cameron, M. D., Kenny, P. J., et al. (2012). Orexin-1 receptor mediation of cocaine seeking in male and female rats. J. Pharmacol. Exp. Ther. 340, 801-809.

Zhu, Y., Miwa, Y., Yamanaka, A., Yada, T., Shibahara, M., Abe, Y., et al. (2003). Orexin receptor type-1 couples exclusively to pertussis toxin-insensitive Gproteins, while orexin receptor type-2 couples to both pertussis toxin-sensitive and -insensitive G-proteins. J. Pharmacol. Sci. 92, 259-266.

Conflict of Interest Statement: The authors declare that the research was conducted in the absence of any commercial or financial relationships that could be construed as a potential conflict of interest.

Received: 09 August 2012; accepted: 26 October 2012; published online: 22 November 2012.

Citation: Kim AK, Brown RM and Lawrence AJ (2012) The role of orexins/hypocretins in alcohol use and abuse: an appetitive-reward relationship. Front. Behav. Neurosci. 6:78. doi: 10.3389/ fnbeh.2012.00078

Copyright (c) 2012 Kim, Brown and Lawrence. This is an open-access article distributed under the terms of the Creative Commons Attribution License which permits use, distribution and reproduction in other forums, provided the original authors and source are credited and subject to any copyright notices concerning any third-party graphics etc. 